\title{
A política de difusão aberta do patrimônio científico
}

Ao findar 2010, temos a satisfação de disponibilizar mais um fascículo da Paidéia. Com esse número fechamos o volume 20, mantendo nosso compromisso com a regularidade da revista, um quesito considerado crucial nos processos de avaliação dos periódicos científicos.

$\mathrm{Na}$ atualidade, é muito comum lermos ou ouvirmos que ciência é, basicamente, ciência comunicada. A ciência contemporânea requer a globalização da comunidade científica, mas também não pode perder o sentido regional. Atualmente, a organização do fluxo de informação científica é feita na rede, em sistema internacional de publicação on line. $\mathrm{Na}$ última década houve excepcional avanço na sustentabilidade das publicações em ambiente digital. No contexto nacional os acervos das revistas são amplamente disponibilizados, ampliando a visibilidade mediante o acesso gratuito ao texto completo.

Quando falamos em ciência comunicada, é preciso lembrar que a publicação pode se dar por diversos meios, com destaque para os periódicos científicos, devido ao controle de qualidade, maior credibilidade, regularidade e visibilidade da informação. O conhecimento científico é, essencialmente, oriundo de pesquisa original, submetida à avaliação por pares (peer review process) e publicada em revista indexada, com atenção à análise de uso e impacto da informação veiculada. A indexação em bases especializadas (como PsycINFO) ou multidisciplinares (como SciELO e LILACS) é o selo de qualidade de uma revista.

Nas revistas de maior prestígio, um dos maiores desafios atuais é a organização e gerenciamento do fluxo elevado de artigos submetidos à avaliação. Cada vez mais dependemos da disponibilidade dos consultores ad hoc para agilizar a tramitação dos manuscritos. Como a pressão por publicar tende a se tornar cada vez mais crescente, fazendo com que o volume de trabalho dos pareceristas aumente exponencialmente, precisaremos buscar soluções inovadoras para esse problema.

A Paidéia vem se destacando como uma revista que prima pela qualidade dos artigos que veicula, selecionando aqueles que efetivamente contribuem com o avanço do conhecimento em Psicologia, Educação e áreas afins. Este fascículo referente ao volume 20 , número 47 , abarca a diversidade de temáticas e enfoques teórico-metodológicos que caracteriza a política editorial da revista.

O primeiro artigo deste fascículo, Validación del cuestionario de auto-reporte de comportamiento antisocial en adolescentes: CACSA, de autoria de Paula Alarcón Bañares, Ricardo Pérez-Luco, Sonia Salvo, Gloria Roa, Katherine Jaramillo e Carla Sanhueza, da Universidad de La Frontera, Chile, apresenta a validação de instrumento elaborado para avaliar o comportamento social de adolescentes chilenos (CACSA). Os autores descrevem o comportamento social de dois grupos: adolescentes escolarizados e adolescentes infratores da lei. Os resultados evidenciam que o questionário mostrou qualidades psicométricas apropriadas e capacidade de discriminação entre os adolescentes escolarizados e os infratores da lei. Os autores discutem a importância de reconhecer a prevalência de comportamentos anti-sociais e a relação entre condutas pró-sociais e anti-sociais em adolescentes chilenos.

O segundo artigo, intitulado Exploração vocacional em adolescentes: avaliação de uma intervenção em classe, de Martina Königstedt e Maria do Céu Taveira, da Universidade do Minho, Portugal, analisa o impacto de uma intervenção psicológica na exploração e tomada de decisão vocacional em 39 alunos e 43 alunas do $9^{\circ}$ ano, com idades entre 13 e 17 anos. Os resultados obtidos reforçam a importância da exploração da carreira na diminuição das dificuldades de tomada de decisão.

O artigo Qualificação profissional a distância: avaliação da transferência de treinamento, de autoria de Thaís Zerbini, da Universidade de São Paulo, campus de Ribeirão Preto, e Gardênia Abbad, da Universidade de Brasília, buscou identificar variáveis explicativas da aplicação de habilidades ensinadas a 470 participantes de um curso de qualificação profissional a distância. Os resultados mostram a ocorrência de maior poder explicativo de variáveis individuais sobre resultados de treinamentos, em comparação com modelos de avaliação de treinamentos presenciais

Ainda no contexto de ensino, o artigo Criatividade no ensino médio segundo seus estudantes, de Janaina Maria Oliveira Almeida, do Instituto de Ensino Superior Cenecista e Colégio do Carmo e Eunice Maria Lima Soriano de Alencar, da Universidade Católica de Brasília, examina a percepção de 217 alunos do ensino médio quanto ao nível de sua criatividade, de seus professores e colegas, bem como a extensão em que práticas docentes utilizadas por seus professores contemplavam a criatividade. Os resultados indicam que os alunos se avaliaram como significativamente mais criativos do que seus professores e colegas. Metade dos estudantes concordou que seus professores têm contemplado o desenvolvimento e a expressão do potencial criativo.

$\mathrm{Na}$ sequência, o artigo Leitura/escrita de crianças: comparações entre grupos de diferentes escolas públicas, de Jerusa Fumagalli de Salles, Maria Alice de Mattos Pimenta Parente e Lia Beatriz de Lucca Freitas, da Universidade Federal do Rio Grande do Sul, traça perfis e compara o desempenho de leitura/escrita de 110 crianças de $2^{a}$ série de cinco escolas. Os resultados indicam que, a despeito de 
serem todas escolas públicas, que atendiam a uma população predominantemente de classe média-baixa, houve variabilidade de desempenhos em leitura e escrita, mais expressiva na escrita e na compreensão de leitura textual. As autoras destacam como relevantes para a compreensão dessa diferença características da escola, da família e do aluno.

Também avaliando crianças, o artigo Crianças pré-escolares e suas concepções de família, de Maria Auxiliadora Dessen e Patrícia Cristina Campos Ramos, da Universidade de Brasília, investiga as concepções de família na perspectiva de 33 pré-escolares, com idades de três, quatro e cinco anos. Os participantes foram divididos em dois grupos: Grupo A (ambos os genitores com ocupação remunerada) e Grupo B (apenas o pai com ocupação remunerada). Houve maior ênfase à função socializadora no Grupo B do que no Grupo A e as definições foram mais abstratas e complexas entre crianças de cinco anos. As autoras sugerem que as concepções das crianças sobre os atuais modos de vida das famílias precisam ser investigadas em uma perspectiva longitudinal e transcultural.

A próxima contribuição, intitulada Acolhimento familiar: caracterização de um programa, de autoria de Lara Barros Martins, Nina Rosa do Amaral Costa e Maria Clotilde Rossetti-Ferreira, da Universidade de São Paulo, campus de Ribeirão Preto, teve por objetivo caracterizar os principais atores envolvidos em um programa de Acolhimento Familiar e os acolhimentos realizados. Dentre os achados deste estudo destacam-se que: a maioria dos acolhidos eram meninos, afrodescendentes, de até seis anos. As famílias acolhedoras eram constituídas por casais com filhos com motivações solidárias para acolher. Como principal causa dos acolhimentos foi citada a negligência. Quanto aos encaminhamentos pós-acolhimento, porcentagem semelhante foi encontrada entre crianças que foram adotadas e as reintegradas às suas famílias. As autoras afirmam a importância do estudo para a formulação de políticas públicas, oferecendo subsídios para a redefinição de práticas de acolhimento familiar.

O próximo artigo, intitulado Desenvolvimento, escolarização e síndrome de Down: expectativas maternas, de Laura Kolberg Lipp, Fernanda de Oliveira Martini e Lisiane Machado de Oliveira-Menegotto, da Universidade Federação de Estabelecimentos de Ensino Superior de Novo Hamburgo, investiga as expectativas maternas em relação ao desenvolvimento e escolarização do filho com síndrome de Down, a partir de uma perspectiva psicanalítica. Os resultados demonstram que as mães apresentaram dificuldade de construir suas expectativas. As autoras ressaltam a importância de oferecer apoio às mães, bem como de professores que acompanharão o aluno com síndrome de Down a partir da idade escolar

$\mathrm{O}$ artigo A banalização da prescrição de psicofármacos em um ambulatório de saúde mental, de Daniele de Andrade Ferrazza, Cristina Amélia Luzio, Luiz Carlos da Rocha e Raphael Rodrigues Sanches, da Universidade Estadual Paulista Júlio de Mesquita Filho, visa problematizar o processo atual de medicalização generalizada da população com sofrimento psíquico. Os dados do estudo são indicativos de que o dispositivo de saúde mental estudado tem uma atuação promotora de medicalização psicofarmacológica, contrária ao movimento de ampliação dos direitos à saúde mental coletiva que a atual Política Nacional de Saúde Mental procura efetivar.

O próximo artigo Dançar o adolescer: estudo fenomenológico com um grupo de dança de rua em uma escola, de Renata Marques Rego Miranda e Vera Engler Cury, da Pontifícia Universidade Católica de Campinas, busca compreender os sentidos atribuídos à experiência de dança de rua por adolescentes. As autoras acompanharam, semanalmente e durante seis meses, as aulas de dança e, posteriormente, realizaram entrevistas individuais com sete alunos. Concluiu-se que a experiência da dança proporcionou aos alunos a emergência de elementos típicos da experiência de adolescer.

A contribuição seguinte é um estudo teórico, intitulado O corpo na escola: mapeamentos necessários, de autoria de Marisa Helena Silva Farah da Universidade de São Paulo. O estudo realiza um mapeamento do corpo na escola, na tentativa de possibilitar aos educadores iniciantes uma construção do olhar para o aluno com seu corpo. A autora encerra seu trabalho com a proposta de reflexão sobre quais seriam as práticas corporais disciplinadoras e seus efeitos nos corpos que as instituições escolares realizam no intuito de manter a ordem e formar alunos para servirem a um tipo de sociedade.

Também de natureza teórica, o artigo $O$ "super-homem" e o "pai da horda”: considerações éticas, de autoria de Simone Perelson, da Universidade Federal do Rio de Janeiro, analisa a aproximação proposta por Freud ao "pai da horda primitiva" e a noção de "super-homem" referida por Nietzsche. O estudo enfatiza os problemas presentes na interpretação freudiana da noção de "super-homem", diferenças entre Freud e Nietzsche no que concernem à compreensão da "autarquia" e da "desconsideração pela lei" e entre o "desprezo pela moral" reivindicado por Freud e a defesa nietzschiana de uma "moral baseada na transmutação de todos os valores".

O próximo estudo é uma revisão da literatura, Adolescência e organização de personalidade borderline: caracterização dos vínculos afetivos, de autoria de Aline Bedin Jordão, da Universidade Federal de Santa Maria e Vera Regina Röhnelt Ramires, da Universidade do Vale do Rio dos Sinos, sobre os vínculos afetivos de adolescentes com indicadores de personalidade borderline. Os resultados foram sistematizados em três núcleos: adolescência e cultura contemporânea, características da organização borderline na adolescência e vínculos afetivos desses adolescentes. O estudo reforça a importância dos vínculos de apego inseguro, a psicopatologia materna e o papel das experiências traumáticas na história de vida desses pacientes.

O relato de experiência profissional, intitulado Oficina sobre sexualidade e namoro para pré-adolescentes, de Daniela Centenaro Levandowski, da Universidade Federal de Ciências da Saúde de Porto Alegre e Márcia Moura Schmidt, do Instituto de Cardiologia do Rio Grande do Sul, descreve 
as atividades realizadas em oficinas sobre sexualidade e namoro para pré-adolescentes, alunos de escolas públicas. As autoras destacam a importância de ações de natureza preventiva para reduzir os riscos psicossociais, abrindo oportunidades para o desenvolvimento saudável dos adolescentes.

Por fim, a última seção destina-se à resenha $A$ ciência psicológica para além de sua interface com a saúde: alguns diálogos, de Fabio Scorsolini-Comin, da Universidade Federal do Triângulo Mineiro. O autor apresenta o livro Investigação científica em Psicologia: Aplicações atuais em saúde, cujos organizadores foram Sônia Regina Pasian, Geraldo Romanelli e Marcus Vinícius da Cunha. Trata-se de uma obra que reuniu os trabalhos produzidos por alunos e seus orientadores dos programas de mestrado e doutorado da Faculdade de Filosofia, Ciências e Letras de Ribeirão Preto da Universidade de São Paulo. Para o autor, o objetivo da coletânea extrapola a reunião de pesquisas sobre saúde e levanta uma relação de mão dupla: a valorização da pesquisa que contribui para a prática, mas também uma prática que fomenta a pesquisa, favorecendo um diálogo tão almejado e igualmente complexo.

Este número se encerra com as Normas de Publicação e, na seqüência, a relação dos consultores $a d$ hoc que colaboraram com a revista em 2010. Esse é o tributo que rendemos a todos que trabalharam arduamente no processo de revisão de pares.

A Paidéia continua aberta a todos os potenciais colaboradores, que desejem oferecer sua parcela de contribuição para aprimorar a qualidade da pesquisa em Psicologia e Educação. Para prepararem seus manuscritos, basta consultarem as normas de publicação no site da SciELO.

Desejamos uma leitura proveitosa a todos.

Manoel Antônio dos Santos

Editor 